\title{
FAKTOR-FAKTOR YANG BERHUBUNGAN DENGAN PERAN PETUGAS KESEHATAN DALAM PENGAWASAN MASA NIFAS DI PUSKESMAS KUTA COT GLIE ACEH BESAR
}

\author{
Anwar Arbi ${ }^{1 *}$, Intan Liana $^{2}$ \\ ${ }^{1}$ Fakultas Kesehatan Masyarakat Universitas Muhamadiyah Aceh, Indonesia \\ 2 Jurusan Keperawatan Gigi Poltekkes Kemenkes Aceh, Indonesia \\ * Korespondensi penulis: anwar_arbie@yahoo.com
}

\begin{abstract}
ABSTRAK
Latar Belakang: Pemantauan dan perawatan kesehatan yang memadai selama kehamilan sampai masa nifas sangat penting untuk kelangsungan hidup ibu dan bayinya. Upaya mempercepat penurunan kematian ibu dalam menekan ketersediaan pelayanan kesehatan ibu di masyarakat. Tujuan penelitian untuk mengetahui faktor yang berhubungan dengan peran petugas kesehatan dalam pengawasan masa nifas di Wilayah Kerja Puskesmas Kuta Cot Glie Kabupaten Aceh Besar tahun 2018.

Metode: Penelitian ini bersifat deskriptif analitik dengan pendekatan cross-sectional. Populasi pada penelitian ini adalah seluruh bidan yang berada di Wilayah Kerja Puskesmas Kuta Cot Glie. Jumlah 36 orang bidan, dengan teknik pengambilan sampel menggunakan total sampling. Pengujian hipotesis dalam penelitian ini menggunakan analisis uji statistik yaitu uji chi square.

Hasil: ada hubungan antara media informasi ( $p$-value 0,048), sikap petugas kesehatan ( $p$-value 0,001), dan akses petugas kesehatan ( $p$-value 0,008 ).

Kesimpulan: ada hubungan antara media informasi, sikap petugas kesehatan dan akses petugas kesehatan dalam pengawasan masa nifas.
\end{abstract}

Kata Kunci : peran petugas kesehatan; pengawasan masa nifas; media informasi; sikap petugas kesehatan; akses petugas kesehatan.

\section{FACTORS RELATED TO THE ROLE OF HEALTH OFFICERS IN SUPERVISING POST PARTUM PERIOD OF KUTA COT GLIE HEALTH CENTER - ACEH BESAR}

\section{ABSTRACT}

Background: Adequate health monitoring and care during pregnancy until the postpartum period is very important for the survival of the mother and her baby. Efforts to accelerate the reduction of maternal mortality in reducing the availability of maternal health services in the community. The purpose of the study was to determine the factors associated with the role of health workers in monitoring the postpartum period in the Kuta Cot Glie Community Health Center Working Area in Greater Aceh District in 2018

Methods: This study was descriptive analytic with a cross-sectional approach. The population in this study were all midwives in the Kuta Cot Glie Community Health Center Working Area. A total of 36 midwives, recruited using total sampling technique. The hypothesis of this study was analysed using chi square test.

Results: It was found that there was a relationship between information media (p-value 0.048), attitudes of health workers (p-value 0.001), and access to health workers (p-value 0.008).

Conclusion: A relationship were found between media information, attitudes of health workers, access to health workers in the supervision of the puerperium.

Keyword: role of health officers; monitoring of postpartum period; media information; attitudes of health officers; access to health officers 


\section{PENDAHULUAN}

Pemantauan dan perawatan kesehatan yang memadai selama kehamilan sampai masa nifas sangat penting untuk kelangsungan hidup ibu dan bayinya. Dalam upaya mempercepat penurunan kematian ibu, Kementerian Kesehatan menekankan pada ketersediaan pelayanan kesehatan ibu di masyarakat. ${ }^{1}$ Seorang bidan yang kompeten dharapkan dapat menangani masalah-masalah yang dihadapi pada masa kehamilan, persalinan, nifas, bayi baru lahir, keluarga berencana, kesehatan reproduksi wanita dan pelayanan kesehatan masyarakat. Maka dari itu, diperlukan pelayanan yang bersifat khusus berupa asuhan kebidanan. ${ }^{2}$

Masa nifas merupakan masa yang cukup penting bagi tenaga kesehatan untuk selalu melakukan pemantauan karena pelaksanaan yang kurang maksimal dapat menyebabkan ibu mengalami berbagai masalah, bahkan dapat berlanjut pada komplikasi masa nifas. ${ }^{3}$

Jika ditinjau dari penyebab kematian para ibu, infeksi merupakan penyebab kematian terbanyak nomor dua setelah perdarahan sehingga sangat tepat jika para tenaga kesehatan memberikan perhatian yang tinggi pada masa ini. Adanya permasalahan ibu akan berimbas juga pada kesejahteraan bayi yang dilahirkannya, karena bayi tersebut tidak akan mendapatkan perawatan maksimal dari ibunya. Dengan demikian, angka morbiditas dan mortalitas bayi pun akan meningkat. ${ }^{3}$

Masa nifas merupakan masa yang rawan bagi ibu, sekitr $60 \%$ kematian ibu terjadi setelah melahirkan dan hampir 50\% dari kematian pada masa nifas terjadi pada 24 jam pertama setelah persalinan, diantaranya disebabkan oleh adanya komplikasi masa nifas. Oleh karena itu, peran dan tanggung jawab bidan untuk memberikan asuhan kebidanan ibu nifas dengan pemantauan mencegah beberapa kematian ini. ${ }^{4}$

Data Dinas Kesehatan Aceh Besar menunjukan bahwa seluruh ibu hamil berjumlah 128.525 jiwa dengan k1 berjumlah 111.809 orang $(87 \%)$ dan $\mathrm{k} 4$ berjumlah 102.144 orang (79\%). Data persalinan yang ditolong oleh tenaga kesehatan sebanyak 100.135 orang (82\%), dan yang mendapat pelayanan kesehatan nifas sebanyak 97.241 orang (79\%). Angka kematian ibu (AKI) dilaporkan berjumlah 88 orang pada tahun 2015, dengan jumlah lahir hidup 6.827 jiwa. Sedangkan Jumlah seluruh ibu hamil 10.647 jiwa dengan k1 sebanyak 7.911 orang $(74 \%)$ dan k4 7.179 orang $(67 \%)$. Data persalinan yang ditolong oleh tenaga kesehatan 7.305 orang $(72 \%)$, dan yang mendapat pelayanan kesehatan nifas sebanyak 6.769 orang
(67\%). Jumlah persalinan di Wilayah Puskesmas Kuta Cot Glie tahun 2017 sebanyak 196 orang, dengan persalinan sectio caesarea sebanyak 36 orang. 5

Masa nifas merupakan masa yang rentan bagi kelangsungan hidup ibu baru bersalin. Sebahagian besar kematian ibu terjadi pada masa nifas sehingga peran petugas kesehatan dalam pengawasan masa nifas berperan penting dalam upaya menurunkan angka kematian ibu. pengawasan masa nifas adalah pengawasan yang dilakukan oleh petugas kesehatan yang diberikan pada ibu selama periode 6 jam sampai 42 hari setelah melahirkan. Selain itu petugas kesehatan harus memberikan informasi-informasi penting selama masa nifas, kebutuhan informasi dan konseling tentang masa nifas merupakan salah satu peran aktif petugas kesehatan.

Survei yang peneliti lakukan langsung pada Wilayah Kerja Puskesmas Kuta Cot Glie Aceh Besar Tahun 2018 yaitu dengan mewawancarai 10 orang ibu nifas yang betempat tinggal di Wilayah Kerja Puskesmas tersebut mendapatkan bahwa ibu yang melahirkan normal dan lebih dari satu kali jarang dilakukan pengawasan masa nifas, dikarenakan usia mereka tergolong sudah mengerti tentang masa nifas, serta kurangnya akses informasi yang menyebabkan ibu kurang memahami pentingnya pengawasan masa nifas. Adapun pemahaman yang dipercayai dan diyakini masyarakat setelah melahirkan ibu sebaiknya tidak banyak bergerak agar tubuhnya cepat segera kembali seperti sebelumnya. Kemudian dari petugas kesehatan, peran petugas sangat penting dalam mengawasi masa nifas. Banyak ibu yang lebih dari satu kali nifas, yang mengatakan bahwa para petugas kesehatan tidak berkunjung ke rumah. Alasannya karena ibu sudah pernah mengalami nifas sebelumnya. Hal ini juga disebabkan oleh kurangnya dukungan petugas kesehatan dalam penyampaian informasi kepada ibu tentang pentingnya pengawasan masa nifas.

Tujuan Penelitian ini adalah untuk mengetahui faktor-faktor yang berhubungan dengan peran petugas kesehatan dalam pengawasan masa nifas di Wilayah Kerja Puskesmas Kuta Cot Glie Kabupaten Aceh Besar tahun 2018 juga untuk mngetahui hubungan promosi kesehatan dalam pengawasan masa nifas, untuk mengetahui hubungan sikap petugas kesehatan dalam pengawasan masa nifas, untuk mengetahui akses pelayanan kesehatan dalam pengawasan masa nifas. 


\section{METODE}

Penelitian ini menggunakan bersifat deskriptif analitik dengan pendekatan cross sectional Populasi dalam penelitian ini adalah keseluruhan petugas kesehatan (Bidan Desa) yang berada di Wilayah Kerja Puskesmas Kuta Cot Glie Kabupaten Aceh besar yang berjumlah 36 orang, dengan menggunakan teknik Tatal sampling, yaitu pengambilan sampel yang dilakukan secara keseluruhan.

Analisa statistik dengan menggunakan uji data Chi-Square pada tingkat kemaknaannya $95 \% \quad(p<0,05)$ Data yang telah dikumpulkan kemudian diolah dan disajikan dalam bentuk tabel distribusi frekuensi, narasi, dan uji statistik.

\section{HASIL DAN PEMBAHASAN}

Distribusi frekuensi peran petugas kesehatan, media informasi, sikap petugas kesehatan dan akses petugas kesehatan di wilayah kerja Puskesmas Cot Glie Aceh Besar ditampilkan pada tabel 1 .

Tabel 1. Distribusi Frekuensi Peran Petugas Kesehatan, Media Informasi, Sikap Petugas Kesehatan dan Akses Petugas Kesehatan di Wilayah Kerja Puskesmas Cot Glie Aceh Besar

\begin{tabular}{lll}
\hline \multicolumn{1}{c}{ Variebel (N=36) } & n & \% \\
\hline Peran Petugas Kesehatan & & \\
$\quad$ Ada & 17 & 47,2 \\
$\quad$ Tidak & 19 & 52,8 \\
Media Informasi & & \\
$\quad$ Ada & 16 & 44,4 \\
$\quad$ Tidak & 20 & 55,6 \\
Sikap Petugas Kesehatan & & \\
$\quad$ Positif & 16 & 44,4 \\
$\quad$ Negatif & 20 & 55,6 \\
Akses Petugas Kesehatan & & \\
$\quad$ Terjangkau & 14 & 38,9 \\
Tidak Terjangkau & 22 & 61,1 \\
\hline
\end{tabular}

Dari tabel 1 diketahui bahwa dari 36 orang responden yang diteliti, sebanyak $47,2 \%$, menyatakan adanya peran petugas kesehatan dalam mengawasi masa nifas, sementara $52,8 \%$ menyatakan tidak ada. Sebanyak 44,4\% menyebutkan adanya media informasi dalam pengawasan masa nifas, sementara 55,6\% tidak ada. Sikap petugas kesehatan yang positif dirasakan sebanyak $44,4 \%$, sedangkan sebanyak $55,6 \%$ merasakan sikap petugas kesehatan yang negative. Akses petugas kesehatan dapat terjangkau pada 38,9\% responden, namun sebagian besar $(61,1 \%)$ tidak dapat menjangkau akses petugas kesehatan.
Tabel 2. Hubungan Media Informasi dengan Peran Petugas Kesehatan dalam Pengawasan Masa Nifas di Wilayah Kerja Puskesmas Kuta Cot Glie Aceh Besar

\begin{tabular}{|c|c|c|c|c|c|c|}
\hline \multirow[t]{3}{*}{$\begin{array}{c}\text { Media } \\
\text { Informasi }\end{array}$} & \multicolumn{4}{|c|}{$\begin{array}{c}\text { Peran Petugas } \\
\text { Kesehatan Dalam } \\
\text { Pengawasan Masa } \\
\text { Nifas }\end{array}$} & \multirow[t]{3}{*}{$\sum$} & \multirow[t]{3}{*}{$\begin{array}{c}p \\
\text { value }\end{array}$} \\
\hline & \multicolumn{2}{|c|}{ Ada } & \multicolumn{2}{|c|}{ Tidak } & & \\
\hline & n & $\%$ & $\mathrm{n}$ & $\%$ & & \\
\hline Ada & 11 & 68,8 & 5 & 31,3 & 16 & 0,048 \\
\hline Tidak Ada & 6 & 30,0 & 14 & 70,0 & 20 & \\
\hline Jumlah & 17 & 47,2 & 19 & 52,8 & 36 & \\
\hline
\end{tabular}

Berdasarkan Tabel 2 di ketahui bahwa adanya media informasi dengan adanya adanya peran petugas kesehatan dalam pengawasan masa nifas sebanyak $68,8 \%$, dan yang tidak ada media informasi dengan adanya peran petugas kesehatan dalam pengawasan masa nifas sebanyak 30,0\%. Sedangkan tidak adanya media informasi dengan tidak ada peran petugas kesehatan dalam pengawasan masa nifas sebanyak $70,0 \%$, dibandingkan yang adanya media informasi dengan tidak adanya peran petugas kesehatan dalam pengawasan masa nifas sebanyak 31,3\%.

Berdasarkan hasil uji statistik uji ChiSquare dengan tingkat kemaknaan $\alpha=0,05$ diperoleh nilai $p$-value 0,048 , menunjukan ada hubungan antara media informasi dengan peran petugas kesehatan dalam pengawasan masa nifas di Wilayah Kerja Puskesmas Kuta Cot Glie Kabupaten Aceh Besar Tahun 2018.

Hasil analisis menunjukan bahwa ada hubungan antara media informasi dengan peran petugas kesehatan dalam pengawasan masa nifas, dimana hasil uji statistik menunjukan bahwa nilai $p$-value 0,048 lebih kecil dari nilai $\alpha$ $<0,05$.

Penelitian ini sesuai dengan hasil penelitian yang menunjukkan tingkat signifikan umur $0,042(\alpha=0,05)$, yang artinya ada hubungan antara media informasi dengan peran petugas kesehatan pada perilaku pasca nifas. ${ }^{6}$

Upaya yang harus dilakukan untuk meningkatkan media informasi tersebut yaitu dengan mengakses internet, poster, tabloid, majalah, koran, konsultasi dengan petugas kesehatan, dengan ikut seminar dan promosi. Promosi kesehatan bukan hanya kegiatan penyadaran masyarakat atau pemberian dan peningkatan pengetahuan masyarakat tentang kesehatan tetapi juga merupakan upaya-upaya dalam menfasilitasi perubahan perilaku kesehatan yang diinginkan. ${ }^{2}$ 
Media informasi pada hakikatnya adalah alat bantu pendidikan untuk menyampaikan informasi kesehatan dan media tersebut sehingga mempermudah penerimaan pesan-pesan kesehatan bagi masyarakat. Perkembangan media informasi juga sebanding dengan pengaruhnya yang semakin kuat terhadap dunia globalisasi saat ini. Pengaruh media sekarang bahkan turut dalam membentuk karakter, perilaku, hingga gaya hidup seseorang. ${ }^{7}$

Asumsi peneliti bahwa semakin banyak mendapatkan informasi maka semakin banyak pula yang harus disampaikan ke pasien oleh petugas kesehatan, sebaliknya jika petugas hanya sedikit memberikan informasi maka semakin sedikit juga pasien mendapatkan informasi. Selain itu juga didukung oleh hasil penelitian bahwanya kurangnya media informasi yang disampaikan atau yang diberikan sehingga pasien kurang memahami tentang maksud petugas kesehatan tersebut.

Tabel 3. Hubungan Sikap Petugas Kensehata dengan Peran Petugas Kesehatan dalam Pengawasan Masa Nifas di Wilayah Kerja Puskesmas Kuta Cot Glie Aceh Besar

\begin{tabular}{|c|c|c|c|c|c|c|}
\hline \multirow[t]{3}{*}{$\begin{array}{c}\text { Sikap Petugas } \\
\text { Kesehatan }\end{array}$} & \multicolumn{4}{|c|}{$\begin{array}{c}\text { Peran Petugas } \\
\text { Kesehatan Dalam } \\
\text { Pengawasan Masa } \\
\text { Nifas } \\
\end{array}$} & \multirow[t]{3}{*}{$\sum$} & \multirow[t]{3}{*}{$\begin{array}{c}p \\
\text { value }\end{array}$} \\
\hline & \multicolumn{2}{|c|}{ Ada } & \multicolumn{2}{|c|}{ Tidak } & & \\
\hline & $\mathbf{n}$ & $\%$ & $\mathbf{n}$ & $\%$ & & \\
\hline$\overline{\text { Positif }}$ & 13 & 81,3 & 3 & 18,8 & 16 & 0,001 \\
\hline Negatif & 4 & 20,0 & 16 & 80,0 & 20 & \\
\hline Jumlah & 17 & 47,2 & 19 & 52,8 & 36 & \\
\hline
\end{tabular}

Berdasarkan Tabel 3 di ketahui bahwa adanya sikap positif dengan adanya adanya peran petugas kesehatan dalam pengawasan masa nifas sebanyak $81,3 \%$, dan sikap negatif dengan adanya peran petugas kesehatan dalam pengawasan masa nifas sebanyak 20,0\%. Sedangkan sikap negatif dengan tidak ada peran petugas kesehatan dalam pengawasan masa nifas sebanyak $80,0 \%$, dibandingkan sikap positif dengan tidak adanya peran petugas kesehatan Dalam pengawasan masa nifas sebanyak $18,8 \%$.

Berdasarkan hasil uji statistik uji ChiSquare dengan tingkat kemaknaan $\alpha=0,05$ diperoleh nilai $\quad$-value 0,001 , menunjukan ada hubungan antara sikap petugas kesehatan dengan peran petugas kesehatan dalam pengawasan masa nifas di Wilayah Kerja Puskesmas Kuta Cot Glie Kabupaten Aceh Besar Tahun 2018.

Hasil analisis menunjukan bahwa ada hubungan antara sikap petugas kesehatan dengan dengan peran petugas kesehatan dalam pengawasan masa nifas, dimana hasil uji statistik menunjukan bahwa nilai $p$-value 0,001 lebih kecil dari nilai $\alpha<0,05$.

Penelitian ini sesuai dengan hasil penelitian dimana adanya nilai signifikansi 0,016 , yang berarti kurang dari 0,05 $(0,016<$ $0,05)$ sehingga dapat disimpulkan bahwa ada Hubungan antara sikap ibu nifas dengan praktik perawatan masa nifas. ${ }^{8}$

Peran petugas kesehatan yang diharapkan yaitu dengan memberikan pelayanan kesehatan kepada masyarakat untuk meningkatkan derajat kesehatan masyarakat. Kemudian informasi dari tenaga kesehatan yang didapat ibu dalam hal ini adalah paritas ibu yang mayoritas telah mempunyai primipara sehingga dapat bersikap positif terhadap masa nifas sedangkan pengaruh dari orang lain berasal dari informasi baik secara langsung yang diperoleh dari dokter atau bidan pada saat kunjungan maupun melalui media masa sehingga ibu dapat bersikap positif dalam deteksi dini komplikasi masa nifas. ${ }^{9}$

Asumsi peneliti bahwa sikap petugas kesehatan yang positif dapat meningkatkan pengawasan masa nifas oleh pasien, sebaiknya jika sikap petugas kesehatan negatif maka pasien akan merasa tidak menyenangkan dan akhirnya kurang kesadaran pasien dalam melakukan perawatan masa nifas. Hal ini mengakibatkan pengawasan masa nifas tidak berjalan optimal.

Tabel 4. Hubungan Akses Petugas Kensehata dengan Peran Petugas Kesehatan dalam Pengawasan Masa Nifas di Wilayah Kerja Puskesmas Kuta Cot Glie Aceh Besar

\begin{tabular}{|c|c|c|c|c|c|c|}
\hline \multirow[t]{3}{*}{$\begin{array}{l}\text { Akses Petugas } \\
\text { Kesehatan }\end{array}$} & \multicolumn{4}{|c|}{$\begin{array}{c}\text { Peran Petugas } \\
\text { Kesehatan Dalam } \\
\text { Pengawasan Masa } \\
\text { Nifas } \\
\end{array}$} & \multirow[t]{3}{*}{$\sum$} & \multirow[t]{3}{*}{$\begin{array}{c}p \\
\text { value }\end{array}$} \\
\hline & \multicolumn{2}{|c|}{ Ada } & \multicolumn{2}{|c|}{ Tidak } & & \\
\hline & $\mathbf{n}$ & $\%$ & $\mathrm{n}$ & $\%$ & & \\
\hline Terjangkau & 11 & 78,6 & 3 & 21,4 & 14 & 0,008 \\
\hline $\begin{array}{l}\text { Tidak } \\
\text { Terjangkau }\end{array}$ & 6 & 27,3 & 16 & 72,7 & 22 & \\
\hline Jumlah & 17 & 42,2 & 19 & 52,8 & 36 & \\
\hline
\end{tabular}

Berdasarkan Tabel 4 diketahui bahwa terjangkaunya akses petugas kesehatan dengan adanya adanya peran petugas kesehatan dalam pengawasan masa nifas sebanyak $78,6 \%$, dan tidak terjangkaunya akses petugas kesehatan dengan adanya peran petugas kesehatan dalam pengawasan masa nifas sebanyak $27,3 \%$. Sedangkan tidak terjangkaunya akses petugas kesehatan dengan tidak ada peran petugas kesehatan dalam pengawasan masa nifas sebanyak $72,7 \%$, dibandingkan terjangkaunya akses petugas kesehatan dengan tidak adanya 
peran petugas kesehatan dalam pengawasan masa nifas sebanyak 21,4\%.

Berdasarkan hasil uji statistik uji ChiSquare dengan tingkat kemaknaan $\alpha<0,05$ diperoleh nilai $p$-value 0,008 , menunjukan ada hubungan antara akses petugas kesehatan dengan peran petugas kesehatan dalam pengawasan masa nifas di Wilayah Kerja Puskesmas Kuta Cot Glie Kabupaten Aceh Besar Tahun 2018.

Hasil analisis menunjukan bahwa ada hubungan antara akses petugas kesehatan dengan dengan peran petugas kesehatan dalam pengawasan masa nifas, dimana hasil uji statistik menunjukan bahwa nilai p-value 0,008 lebih kecil dari nilai $\alpha<0,05$.

Penelitian ini sesuai dengan hasil penelitian dimana adanya nilai signifikansi 0,028 , yang berarti kurang dari $0,05(0,016<$ $0,05)$ sehingga dapat disimpulkan bahwa ada Hubungan antara jarak dengan praktik perawatan masa nifas. ${ }^{8}$

Kendala jarak tempuh dapat diatasi jika akses menuju puskesmas ini dipermudah dengan jalan meningkatkan sarana dan prasarana transportasi yang ada. Faktor keterpencilan, sulit, dan mahalnya transportasi merupakan hambatan untuk menjangkau Puskesmas sehingga kunjungan masyarakat yang bertempat tinggal lebih dekat dari puskesmas lebih banyak jika dibanding dengan masyarakat yang jaraknya jauh. $^{10}$

Jarak tempuh yang merupakan penghalang yang meningkatkan kecenderungan penundaan upaya seseorang atau masyarakat dalam mencari pelayanan kesehatan. Masyarakat diharapkan dapat memanfaatkan pelayanan kesehatan. ${ }^{10}$

Asumsi peneliti bahwa akses petugas kesehatan yang terjangkau membuat petugas dapat mellakukan tugasnya yaitu dapat melakukan pengawasan masa nifas dengan sebaiknya, sebaliknya jika akses petugas kesehatan tidak terjangkau maka tingkat pengawasan masa nifas kurang dilakukan. Hal ini membuat pasien kurang melakukan perawatan masa nifas.

\section{KESIMPULAN}

Berdasarkan hasil penelitian tersebut, maka dapat disimpulkan: ada hubungan antara media informasi, sikap petugas kesehatan, akses petugas kesehatan dalam pengawasan masa nifas. $(p<0,05)$. Dari hasil tersebut maka disarankan kepada Bidan selaku petugas kesehatan di wilayah kerja Puskesmas Kuta Cot
Glie agar memberikan informasi dalam hal pengawasan masa nifas, agar tingkat kesakitan dapat menurun. Sikap petugas kesehatan yang harus lebih peduli dengan pasien, kemudian pada akses petugas yang memadai sehingga pasien mendapatkan pengawasan masa nifas.

\section{DAFTAR PUSTAKA}

1. Riskesdas 2013. Riset Kesehatan Dasar. Badan Penelitian dan Penembangan Kesehatan Kementrian Kesehatan RI. www.depkes.go.id (diakses 15 Agustus 2018).

2. Saifuddin, AB., at al. Buku Acuan Nasional Pelayanan Kesehatan Maternal dan Neonatal. Jakarta: PT. Bina Pustaka Sarwono Prawihardjo. 2013

3. Sulistyawati, A. Buku Ajar Asuhan Kebidanan Pada Ibu Nifas. Yogyakarta: Andi. 2009.

4. Eldawati, S. Hubungan Pengetahuan dan Sikap Ibu Nifas Dengan praktik Perawatan Masa Nifas Di Kecamatan Gunungpati Kota Semarang Bulan jamuari-Maret 2015. Badan Gizi Kesehatan Masyarakat Fakultas Kesehatan Masyarakat: Universitas dipenogoro. Jurnal Kesehatan Masyarakat. 2015; 3(3).

5. Dinkes Aceh Besar. Profil Kesehatan Kabupaten Aceh BesarTahun 2016. Aceh Besar. 2016.

6. Nurjanah F, Isnaeni Y. Hubungan Peran Petugas Kesehatan dan Media Informasi dengan Perilaku Seksual Ibu Pascanifas di Puskesmas Mergangsan (Doctoral dissertation, STIKES' Aisyiyah Yogyakarta). 2014

7. Lestari, Y, A. Komunikasi \& Konseling dalam Praktik Kebidanan. Jakarta: CV. Trans Info Media. 2010.

8. Nurjasmi, E. Buku Acuan Midwifery Update. Jakarta: PP IBI. 2016

9. Setiadi. Keperawatan Keluarga. EGC: Jakarta. 2008.

10. Pohan. Jaminan Mutu Layanan kesehatan: dasardasar pengertian dan penerapan .Jakarta: Buku Kedokteran EGC. 2007. 